\title{
Near-Field Noise Computation for a Subsonic Coannular Jet
}

Ching Y. Loh

Taitech, Inc., Beavercreek, Ohio

Lennart S. Hultgren and Philip C.E. Jorgenson

Glenn Research Center, Cleveland, Ohio 


\section{NASA STI Program . . . in Profile}

Since its founding, NASA has been dedicated to the advancement of aeronautics and space science. The NASA Scientific and Technical Information (STI) program plays a key part in helping NASA maintain this important role.

The NASA STI Program operates under the auspices of the Agency Chief Information Officer. It collects, organizes, provides for archiving, and disseminates NASA's STI. The NASA STI program provides access to the NASA Aeronautics and Space Database and its public interface, the NASA Technical Reports Server, thus providing one of the largest collections of aeronautical and space science STI in the world. Results are published in both non-NASA channels and by NASA in the NASA STI Report Series, which includes the following report types:

- TECHNICAL PUBLICATION. Reports of completed research or a major significant phase of research that present the results of NASA programs and include extensive data or theoretical analysis. Includes compilations of significant scientific and technical data and information deemed to be of continuing reference value. NASA counterpart of peer-reviewed formal professional papers but has less stringent limitations on manuscript length and extent of graphic presentations.

- TECHNICAL MEMORANDUM. Scientific and technical findings that are preliminary or of specialized interest, e.g., quick release reports, working papers, and bibliographies that contain minimal annotation. Does not contain extensive analysis.

- CONTRACTOR REPORT. Scientific and technical findings by NASA-sponsored contractors and grantees.

- CONFERENCE PUBLICATION. Collected papers from scientific and technical conferences, symposia, seminars, or other meetings sponsored or cosponsored by NASA.

- SPECIAL PUBLICATION. Scientific, technical, or historical information from NASA programs, projects, and missions, often concerned with subjects having substantial public interest.

- TECHNICAL TRANSLATION. Englishlanguage translations of foreign scientific and technical material pertinent to NASA's mission.

Specialized services also include creating custom thesauri, building customized databases, organizing and publishing research results.

For more information about the NASA STI program, see the following:

- Access the NASA STI program home page at http://www.sti.nasa.gov

- E-mail your question via the Internet to help@ sti.nasa.gov

- Fax your question to the NASA STI Help Desk at 301-621-0134

- Telephone the NASA STI Help Desk at 301-621-0390

- Write to: NASA Center for AeroSpace Information (CASI) 7115 Standard Drive Hanover, MD 21076-1320 
NASA/TM-2008-215033

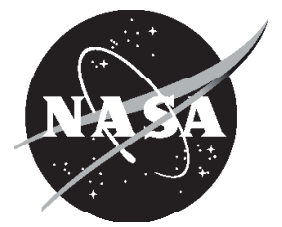

\section{Near-Field Noise Computation for a Subsonic Coannular Jet}

Ching Y. Loh

Taitech, Inc., Beavercreek, Ohio

Lennart S. Hultgren and Philip C.E. Jorgenson

Glenn Research Center, Cleveland, Ohio

Prepared for the

13th AIAA/CEAS/28th AIAA Aeroacoustics Conference

sponsored by the American Institute of Aeronautics and Astronautics and the Confederation of European Aerospace Societies

Rome, Italy, May 21-23, 2007

National Aeronautics and

Space Administration

Glenn Research Center

Cleveland, Ohio 44135 


\section{Acknowledgments}

The authors thank D. Koch for providing the 3BB time-averaged experimental data and nozzle geometry and for helpful discussions. This work received support from the NASA Fundamental Aeronautics Subsonic Fixed Wing and Supersonics Project Offices.

This report contains preliminary findings, subject to revision as analysis proceeds.

Trade names and trademarks are used in this report for identification only. Their usage does not constitute an official endorsement, either expressed or implied, by the National Aeronautics and Space Administration.

Level of Review: This material has been technically reviewed by technical management.

Available from

NASA Center for Aerospace Information 7115 Standard Drive

Hanover, MD 21076-1320
National Technical Information Service 5285 Port Royal Road Springfield, VA 22161

Available electronically at http://gltrs.grc.nasa.gov 


\title{
Near-Field Noise Computation for a Subsonic Coannular Jet
}

\author{
Ching Y. Loh \\ Taitech, Inc. \\ Beavercreek, Ohio 45430 \\ Lennart S. Hultgren and Philip C.E. Jorgenson \\ National Aeronautics and Space Administration \\ Glenn Research Center \\ Cleveland, Ohio 44135
}

\begin{abstract}
A high-Reynolds-number, subsonic coannular jet is simulated, using a three-dimensional finite-volume LES method, with emphasis on the near field noise. The nozzle geometry used is the NASA Glenn 3BB baseline model. The numerical results are generally in good agreement with existing experimental findings.
\end{abstract}

\section{Introduction}

The reduction of aircraft noise is an important issue due to environmental regulations and economic consequences of airport community noise. For modern commercial aircraft engines at subsonic speeds, turbulent mixing noise generated in the jet flow is, in general, a major noise component and is dominant at takeoff. The study of jet noise has been a vital part of aeroacoustics for over half a century and continues to be a topic of many experimental and theoretical investigations; Refs. 1-3 provide a comprehensive discussion and further references. A rapid advance in its understanding has occurred during the past decade, perhaps in conjunction with the development of computational aeroacoustics (CAA) and of improved measurement techniques. The issues, challenges, and contributions of CAA are discussed in Refs. 4-6 and Refs. 7-12 provide examples of advances in experimental methods.

Fine scale turbulence in jet shear flow produces sound propagating predominantly in the lateral $\left(90^{\circ}\right)$ direction, ${ }^{13-16}$ whereas the convection/evolution of large-scale turbulence structures in the jet produces sound propagating downstream at angles close to the jet axis. The work in this paper concerns the sound produced by the large-scale structures in subsonic jets.

Substantial progress in numerical computation of jet mixing noise associated with large-scale structures has been made during recent years by using large-eddy simulation (LES) techniques. Mankbadi et al. ${ }^{17}$ performed an axisymmetric LES computation of a supersonic, high-Reynolds-number jet and determined its far-field radiated sound using an acoustic analogy technique. Zhao et al., ${ }^{18}$ Bogey et al., ${ }^{19}$ and Uzun et al. ${ }^{20}$ computed jet flow and the associated noise by using fully three-dimensional LES at a Mach number of 0.9 . The Reynolds numbers in these simulations were low to moderate; 5, 000, 65, 000, and 100, 000, respectively. DeBonis and Scott ${ }^{21}$ and Loh and Hultgren ${ }^{22}$ used LES to calculate the hydrodynamics of a high-Reynolds-number, supersonic jet of Mach number 1.4. ${ }^{8,9}$ More recent work and discussions of the state-of-the-art can be found in Refs. 23-26. Except for our own work, ${ }^{22}$ which utilized the second-order (in space and time) finite-volume CE/SE Navier-Stokes solver, the numerical schemes used by the above were of high-order finite-difference type. Recent LES studies of coaxial jets have also been carried out by Refs. 27,28.

The present paper utilizes an enhanced time-accurate, upwind, finite-volume scheme for compressible flows on unstructured grids. ${ }^{29}$ The method (ETAU) is nominally second-order accurate in space and time and is capable of yielding high resolution in the presence of sharp gradients. A built-in dissipation model helps to overcome potential pathological behaviors ${ }^{30,31}$ of upwind schemes and renders the ETAU scheme robust and viable for practical computations.

\section{The Jet Flow}

The current computation is for a subsonic dual-stream flow issuing from the NASA Glenn 3BB baseline coannular nozzle, ${ }^{32}$ see Fig. 1, into a co-flow stream of Mach number 0.28 . The nozzle operational conditions corre- 
spond to the ones used by Koch et al. ${ }^{32}$ in their comparison of numerical RANS results with experimental data.

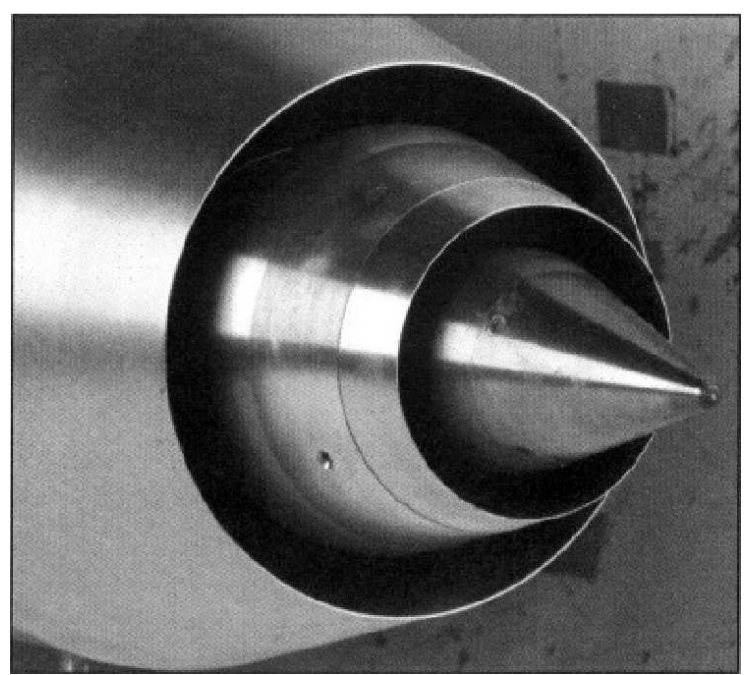

Figure 1. NASA Glenn baseline nozzle, 3 BB $^{32}$
In what follows, the exit diameter $D$ of the of the core nozzle, the density $\rho_{\infty}$, the speed of sound $a_{\infty}$, and the (static) temperature $T_{\infty}$ in the co-flow are used as scales to make all the dependent variables nondimensional. Ideal nozzle flow is fully determined by specifying the back-pressure ratio (ambient static pressure divided by stream total pressure) and the total temperature of the stream. To determine the plenum conditions, the only additional information needed is the ratio of the plenum and exit areas.

Using the ideal gas isentropic relations it follows that for non-choked flow in a nozzle

$$
1<P_{t o t} / P_{\infty}<P_{t o t} / P_{\star}=[(\gamma+1) / 2]^{\gamma /(\gamma-1)}
$$

where $P_{t o t}, P_{\infty}$, and $P_{\star}$ denote the total, back, and sonic pressures, and $\gamma=C_{p} / C_{v}$ is the ratio of specific heats. Within the restrictions of Eq. 1, it follows that the nondimensional nozzle exit conditions are

$$
P_{e}=P_{\infty}=1 / \gamma, \quad \rho_{e}=1 / T_{e}, \quad T_{e}=T_{t o t}\left(P_{\infty} / P_{t o t}\right)^{(\gamma-1) / \gamma}, \quad\left|\mathbf{u}_{e}\right|=M_{e} \sqrt{T_{e}},
$$

where $\rho, T$, and $\mathbf{u}=(u, v, w)$ denote density, temperature, and velocity vector; and the exit Mach number is given by

$$
M_{e}=\sqrt{2\left[\left(P_{t o t} / P_{\infty}\right)^{(\gamma-1) / \gamma}-1\right] /(\gamma-1)} .
$$

Conservation of mass in combination with the ideal gas isentropic relations can be used to show that

$$
M_{r} /\left[1+\frac{1}{2}(\gamma-1) M_{r}^{2}\right]^{\frac{\gamma+1}{2(\gamma-1)}}=\left(A_{e} / A_{r}\right) M_{e} /\left[1+\frac{1}{2}(\gamma-1) M_{e}^{2}\right]^{\frac{\gamma+1}{2(\gamma-1)}},
$$

where $A_{r} / A_{e}$ is the ratio of the plenum (reservoir) and exit areas. Since $M_{e}$ is known from Eq. 3 for a given backpressure ratio, the right-hand side of Eq. 4 is also known, once the area ratio is specified, and hence the plenum Mach number, $M_{r}$ can be determined iteratively. The nondimensional plenum conditions are then obtained using

$$
P_{r}=P_{t o t} /\left[1+\frac{1}{2}(\gamma-1) M_{r}^{2}\right]^{\frac{\gamma}{\gamma-1}}, \quad \rho_{r}=\gamma P_{r} / T_{r}, \quad T_{r}=T_{t o t} /\left[1+\frac{1}{2}(\gamma-1) M_{r}^{2}\right], \quad\left|\mathbf{u}_{r}\right|=M_{r} \sqrt{T_{r}} .
$$

Eqs. 3-5 together with the nozzle conditions in Table 1 fully define the mean flow.

Table 1. Nondimensional Nozzle Flow Conditions

\begin{tabular}{|c|c|c|c|c|c|}
\hline \multicolumn{2}{|c|}{ Core Stream } & \multicolumn{2}{c|}{ Fan Stream } & \multicolumn{2}{c|}{ Free Stream } \\
\hline$P_{\text {tot }} / P_{\infty}$ & 1.6801 & $P_{\text {tot }} / P_{\infty}$ & 1.8301 & $P_{\text {tot }} / P_{\infty}$ & 1.0560 \\
\hline$T_{\text {tot }} / T_{\infty}$ & 2.8320 & $T_{\text {tot }} / T_{\infty}$ & 1.1328 & $T_{\text {tot }} / T_{\infty}$ & 1.0157 \\
\hline$A_{r} / A_{e}$ & 2.7762 & $A_{r} / A_{e}$ & 2.9327 & $M_{\infty}$ & 0.28 \\
\hline
\end{tabular}

\section{Numerical Method}

The numerical scheme adopted in this work is an extension to unstructured hexahedral grids of the low-dissipation, three-dimensional, finite-volume ETAU scheme. ${ }^{29}$ It is applied to an LES version of the compressible Navier-Stokes equations. The ETAU scheme has formal second-order accuracy in both space and time. It has an additional small amount of omni-directional numerical dissipation, compared to standard (see Ref. 33) upwind schemes, that renders it capable of handling a broad range of flow regimes. 


\section{A. Computational Domain and Unstructured Hexahedral Grid}

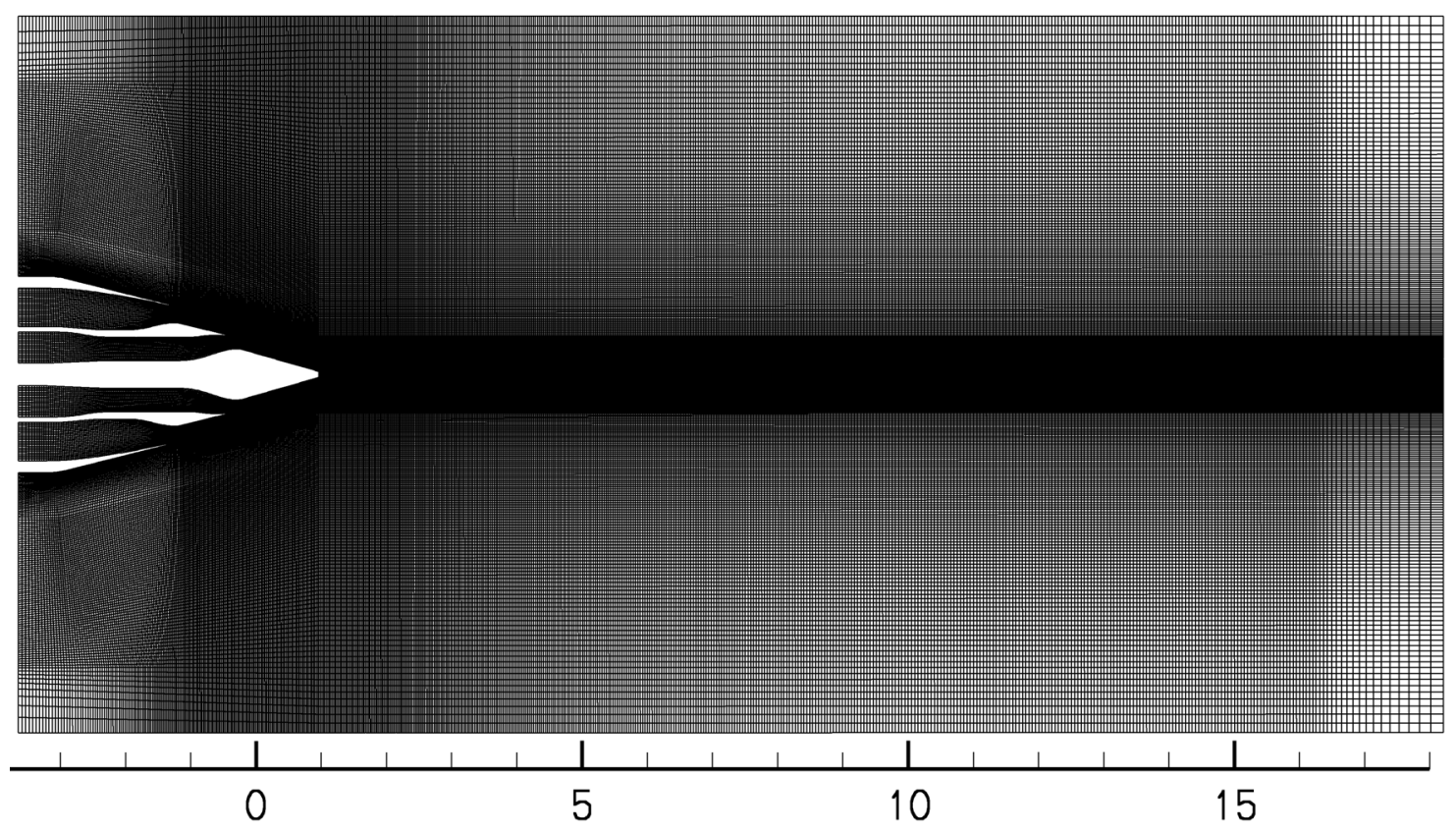

Figure 2. Geometry of the computational domain; the core-nozzle exit diameter is used as length scale.

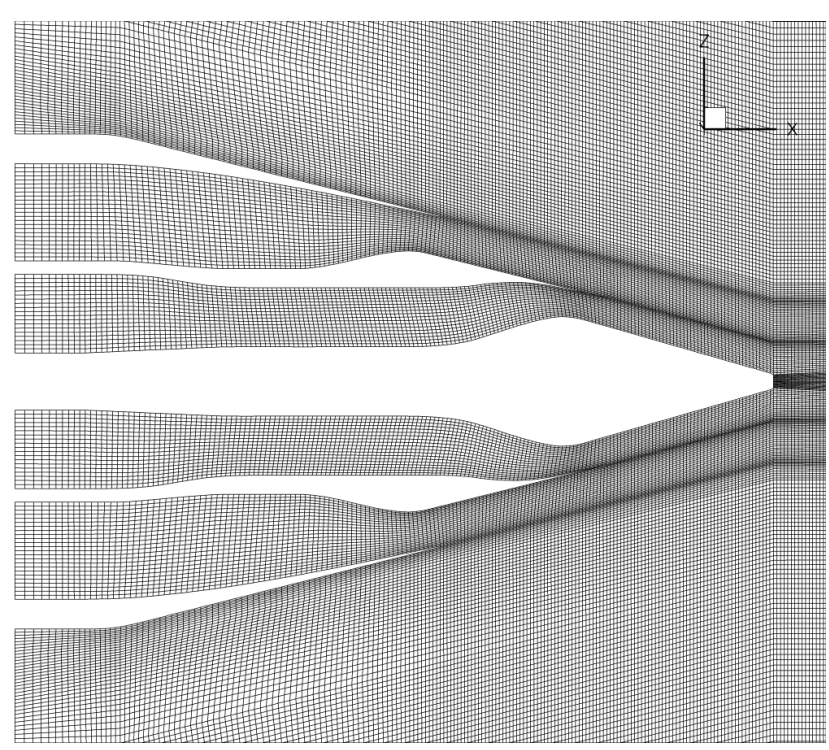

Figure 3. Close-up of Computational Grid Plane
The computational domain including the coannular nozzle is sketched in Fig. 2, with a close-up in Fig 3. It ranges from $x=-3.64$ to $x=18.20$, where $x$ is the streamwise coordinate. The domain diameter is about 11. The numerical simulation begins at the inlets of the coannular nozzle. The fan nozzle exit is at $x=-1.06$; the core nozzle exit is at $x=0$; and the centerbody ends at $x=0.97$.

For fully three-dimensional computations of complicated problems such as the current jet noise problem where several distinct and disparate length scales need to be resolved, ${ }^{4}$ a large number of computational cells are needed to provide sufficient numerical resolution. The choice of an unstructured hexahedral grid for the ETAU method leads to a significant reduction of the number of computational cells, with an associated reduction in computer memory and CPU time requirements, as compared to the commonly used tetrahedral one. The drawback is a modest increase in numerical dissipation.

The unstructured hexahedral grid is generated using the Gridgen ${ }^{34}$ software package. The streamwise step size $\Delta x$ ranges from 0.022 at the nozzle exit $(x=0)$ to

about 0.05 at $x=16.2$. Between $x=16.2$ and $x=18.2$ there is a buffer zone in which $\Delta x$ increases exponentially in size to provide high numerical damping. In total there are about 5.36 million cells in the computational domain, including the buffer zone. The domain covers the near-field region which is the source region for the noise.

Employing a hexahedral grid instead of a tetrahedral one for the current ETAU scheme helps to reduce the number of cells from tens of millions to a few millions. Still, the number of computational cells is very large and the simulation is implemented using parallel-computation techniques. To accomplish this, the unstructured hexahedral grid generated for the entire computational domain is decomposed into subdomains (128 at present) using the efficient mesh parti- 
tioning code METIS. ${ }^{35}$ The ETAU flow solver uses the message-passing-interface (MPI) library to exchange pertinent information between neighboring subdomains during the simulation.

\section{B. Conservation Form of the Three-Dimensional Unsteady Compressible Navier-Stokes Equations}

The Navier-Stokes equations for a perfect gas can be written in the following nondimensional vector form, e.g. Ref. 36:

$$
\boldsymbol{U}_{t}+\boldsymbol{F}_{x}+\boldsymbol{G}_{y}+\boldsymbol{H}_{z}=\mathbf{0},
$$

where $x, y$, and $z$ are the streamwise, transverse, and spanwise coordinates, and $t$ is time. The five components of the conservative flow variable vector $\boldsymbol{U}$ are the density, the three momentum components, and the total energy per unit volume, i.e.,

$$
\begin{gathered}
U_{1}=\rho, \quad U_{2}=\rho u, \quad U_{3}=\rho v, \quad U_{4}=\rho w, \\
U_{5}=p /(\gamma-1)+\rho\left(u^{2}+v^{2}+w^{2}\right) / 2,
\end{gathered}
$$

where, as before, $\rho, u$, and $p$ denote the density, streamwise velocity, and static pressure, and $v$ and $w$ denote the transverse and spanwise velocities. The flux vectors in the $x, y$, and $z$ directions, $\boldsymbol{F}, \boldsymbol{G}$, and $\boldsymbol{H}$, respectively, have both inviscid and viscous contributions and the details of these flux components may be found in a textbook ${ }^{36}$ or in a previous paper $^{37}$ by the present authors.

The nondimensional equations above could form the basis for a direct numerical simulation (DNS). Currently, this is not feasible for the high-Reynolds-number flows of interest here. The present computations are of the LES type, where the effects of the unresolved scales, i.e., scales smaller than the grid resolution, are modeled. In this case, the equations above are considered the filtered ones governing the resolved scales, where $\rho$ and $p$ are interpreted as simply averaged and the other dependent variables are interpreted as Favre, (i.e., density-weighted) averaged over the subgrid scale. The simplest model for the effects of the unresolved scales, or subgrid scales (SGS), on the motion is obtained by using a Boussinesq eddy-diffusivity assumption for the subgrid shear stresses and heat flux coupled by Smargorinsky's model for the eddy viscosity (eg. Ref. 38). The nondimensional viscosity $\mu$, occurring in the viscous contribution to the flux terms in Eq. 6, is then replaced by

$$
\mu=1 / R e+\left(C_{s} \delta\right)^{2}\left(S_{i j} S_{i j}\right)^{1 / 2},
$$

where $S_{i j}=\frac{1}{2}\left(\frac{\partial u_{i}}{\partial x_{j}}+\frac{\partial u_{j}}{\partial x_{i}}\right)$ is the Favré averaged rate-of-strain tensor, $\delta=(\delta x \delta y \delta z)^{1 / 3}$ is a local measure of the grid size, $C_{s}$ is a (nondimensional) constant, and $R e=a_{\infty} D / \nu_{\infty}$ is the Reynolds number for the computation. The inverse Reynolds number $1 / R e=1.8 \times 10^{-6}$ in the present computations. Also, note that the simplifying assumption is also made that the subgrid-scale Prandtl number equals the laminar one, which is taken to have the value 0.72 .

Note that Fureby and Grinstein ${ }^{39}$ point out that applying flux limiters to finite-volume methods (as is done in the current ETAU scheme), even in the absence of any explicit LES assumptions, effectively leads to LES schemes with minimal implicit SGS models. They demonstrated through an 'error' analysis of a particular scheme that the fluxlimiters (essentially low-pass frequency filters) build into the algorithm produces additional terms in the equivalent differential forms of the momentum and energy equations that can be interpreted as the SGS stress tensor and flux, respectively. Hence, there is an additional implicit SGS model inherent in the particular ETAU scheme used in addition to the explicit assumption in Eq. 7.

\section{Enhanced Time-Accurate Upwind Scheme}

By considering $(x, y, z, t)$ as coordinates of a four-dimensional Euclidean space, $E_{4}$, and using the Gauss divergence theorem, it follows that Eq. 6 is equivalent to the following integral conservation law:

$$
\oint_{S(V)} \boldsymbol{I}_{m} \cdot \mathrm{d} \boldsymbol{S}=\mathbf{0}, \quad m=1,2, \ldots, 5
$$

where $S(V)$ denotes the surface around a volume $V$ in $E_{4}$ and $\boldsymbol{I}_{m}=\left(F_{m}, G_{m}, H_{m}, U_{m}\right)$. These equations are discretized, using an unstructured hexahedral grid, with the flow variables stored at each cell center.

Consider the flow variable $\boldsymbol{U}$ and its spatial derivatives, $\boldsymbol{U}_{x}, \boldsymbol{U}_{y}$, and $\boldsymbol{U}_{z}$, as known at the cell centers at time level $n$. The evolution step of the enhanced time-accurate upwind scheme then advances the value at a cell center $i$ to time level $n+1$ through

$$
\boldsymbol{U}_{i}^{(n+1)}=\beta \tilde{\boldsymbol{U}}_{i}+(1-\beta) \boldsymbol{U}_{i}^{(n)}-\frac{\Delta t}{\Delta v} \sum_{k=1}^{12}\left[\boldsymbol{F}_{k}^{(n+1 / 2)} n_{x k}+\boldsymbol{G}_{k}^{(n+1 / 2)} n_{y_{k}}+\boldsymbol{H}_{k}^{(n+1 / 2)} n_{z k}\right] \Delta s_{k},
$$


where $\boldsymbol{F}_{k}, \boldsymbol{G}_{k}, \boldsymbol{H}_{k}, n_{x k}, n_{y_{k}}, n_{z k}$, and $\Delta s_{k}$, are the three flux vectors evaluated for half a time step at the centers of the twelve triangular surfaces that define the hexahedral cell, the corresponding out-going unit normal vector components, and areas, respectively; $\Delta v$ is the volume of the hexahedral cell and $\Delta t$ is the time step; $\tilde{\boldsymbol{U}}_{i}$ is an average based on the values in the six surrounding cells at time step $n$ and $\beta$ is a parameter $(0 \leqslant \beta<1)$. Here, $\tilde{\boldsymbol{U}}_{i}$ is taken to be the simple average of the 12 right states at time level $n$,

$$
\tilde{\boldsymbol{U}}_{i}=\frac{1}{12} \sum_{k=1}^{12}\left(\boldsymbol{U}_{j}^{(n)}+\boldsymbol{U}_{x_{j}}^{(n)} \Delta x_{k}+\boldsymbol{U}_{y_{j}}^{(n)} \Delta y_{k}+\boldsymbol{U}_{z_{j}}^{(n)} \Delta z_{k}\right) \quad j=j(k),
$$

where the right states are linear Taylor series extrapolations from the corresponding neighboring cell center, $j(k)$, to the surface center, $k$. For $\beta=0$, Eq. 9 reduces to the usual update formula for an upwind scheme that provides the cell-averaged values at the next time level. The flux vectors are generated using a Riemann solver, where the required right and left states are obtained by linear Taylor expansion, in both space and time, and Cauchy-Kowaleswki/LaxWendroff time stepping. ${ }^{29}$ Each right state involves only the appropriate neighboring cell and the corresponding left state only involves the current cell. The excluded case $\beta=1$, in a sense, corresponds to the previously used ${ }^{22,40}$ $\mathrm{CE} / \mathrm{SE}$ scheme, except of course a Riemann solver is not used to obtain the surface flux vectors in that method. The value $\beta=0.01$ is used throughout the present work.

The reconstruction step of the ETAU scheme then obtains the flow variable $\boldsymbol{U}$ as a linear vector function within each cell $i$ at the new time level $n+1$ by determining the spatial derivatives at each cell center, $\boldsymbol{U}_{x_{i}}^{(n+1)}, \boldsymbol{U}_{y_{i}}^{(n+1)}$, and

$\boldsymbol{U}_{z_{i}}^{(n+1)}$. This procedure uses the updated flow variable information at the current cell center and its six adjacent cells and leads to an over-determined system. Similarly to Ref 29, a multidimensional van Albada limiter ${ }^{41}$ is applied to obtain the required solution. The evolution/reconstruction procedure can then be repeated to march the solution further in time.

\section{Initial and Boundary Conditions}

Initially, the flow of the entire computational domain is set at the ambient flow conditions, i.e.,

$$
\begin{gathered}
\rho_{0}=1, \quad p_{0}=\frac{1}{\gamma}, \\
u_{0}=M_{\infty}, \quad v_{0}=0, \quad w_{0}=0 .
\end{gathered}
$$

At the exterior upstream inlet boundary, the conservative flow variables are specified to be the same as the ambient flow and their spatial derivatives are held at zero. At the nozzle inlets, the reservoir conditions as described in $\S$ II are imposed. Of course, $v_{r}, w_{r}$, and all spatial derivatives are held at zero.

Non-reflecting boundary conditions ${ }^{42,43}$ are imposed at the circumferential and outflow boundaries. The slip boundary condition is applied on all the nozzle walls, external as well as internal, except on the external centerbodies for both fan and core streams where the no-slip condition is applied.

\section{E. Artificial Forcing}

As is common, e.g. Ref 19, in numerical studies of jet mixing noise, the simulation allows for a low-level, artificial excitation, or turbulence seeding, of the initial jet shear layers. This seeding is accomplished by adding divergencefree velocity perturbations inside the jet shear layers near the nozzle lips. The disturbances are temporally random and are of the vortex-ring form used in, ${ }^{19}$ namely

$$
\begin{gathered}
u^{\prime}=\frac{r-r_{p}}{r} \mathcal{F}\left(x, r, \theta ; x_{p}, r_{p}\right), \\
\left(\begin{array}{c}
v^{\prime} \\
w^{\prime}
\end{array}\right)=-\frac{x-x_{p}}{r} \mathcal{F}\left(x, r, \theta ; x_{p}, r_{p}\right)\left(\begin{array}{c}
\cos \theta \\
\sin \theta
\end{array}\right),
\end{gathered}
$$

where

$$
\mathcal{F}\left(x, r, \theta ; x_{p}, r_{p}\right)=\frac{2 \delta_{p} r_{p}}{\Delta_{p}} \exp \left(-d^{2} \ln 2 / \Delta_{p}^{2}\right) \sum_{n=1}^{16} \epsilon_{n} \cos \left(n \theta+\phi_{n}\right)
$$

and $r=\left(y^{2}+z^{2}\right)^{1 / 2}$ and $\theta=\sin ^{-1}(z / r)$ are the radial and azimuthal coordinates; $x_{p}, r_{p}$ and $\Delta_{p}=0.02$ define the location and spatial extent of the perturbation, and $d=\left[\left(x-x_{p}\right)^{2}+\left(r-r_{p}\right)^{2}\right]^{1 / 2} ; \epsilon_{n}$ and $\phi_{n}$ are uniformly 
distributed random numbers between -1 and 1 , and 0 and $2 \pi$, respectively. They represent the random perturbation amplitude and phase, and are independently generated for the two shear-layers at every time step. For the co-flow/fan shear layer, $x_{p}=-0.99$ and $r_{p}=1.0$; and for the fan/core shear layer, $x_{p}=0.05$ and $r_{p}=0.5$. The overall perturbation amplitude $\delta_{p}$ is, in general, set to 0.003 in the present computations. This value is representative of a typical disturbance environment for laminar-nozzle flow. The perturbations above are then directly added to the velocity field.

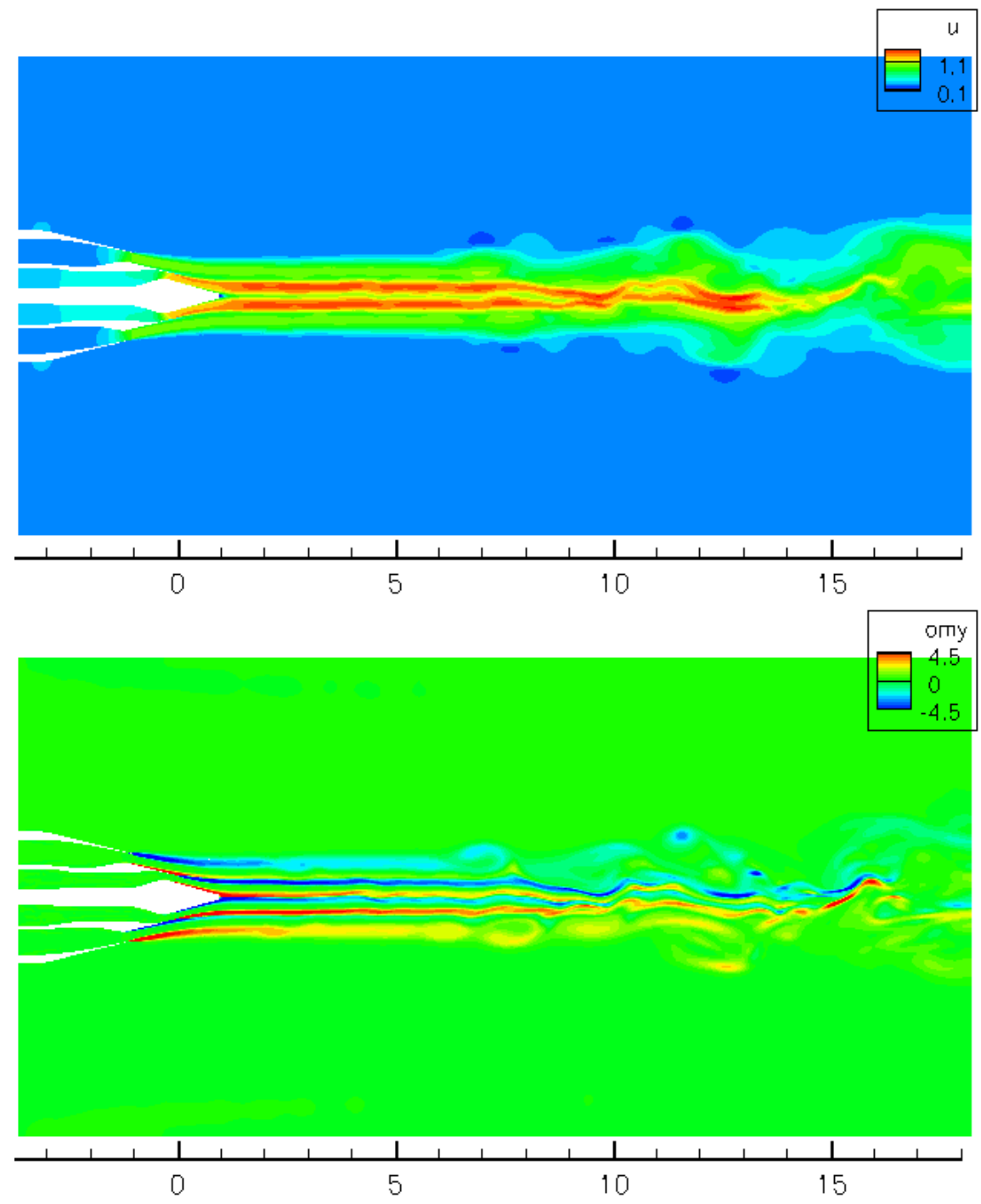

Figure 4. Instantaneous distributions in a spanwise plane at $t=440$, random forcing; top, streamwise velocity; bottom, spanwise vorticity

\section{Numerical Results}

The simulation starts from the uniform initial conditions described above with the artificial forcing turned on using an amplitude $\delta_{p}=0.003$. The simulation is first run to $t=100$, or 100,000 time steps ( $\Delta t=0.001$ ), to ensure that all start-up transients are convected out of the computational domain and that the jet flow is fully established. This time, $t=100$, corresponds roughly to five acoustic times. The acoustic time is a measure of how long it takes a sound wave to pass through the external computational domain. The simulation is then run for an additional 340, 000 time steps to $t=440$, or approximately an additional 17 acoustic times, to achieve sufficient accuracy in the spectral analysis of time series data that is saved at various locations in the computation domain every 20 time steps. 


\section{A. Instantaneous Flow Fields}

Figure 4 shows the computed instantaneous streamwise velocity (top) and spanwise vorticity (bottom) fields in the spanwise plane, $z=0$, at $t=440$. The instantaneous vorticity field, in particular, indicates that the outer core starts to disappear, or merge with the inner core at about 5 diameters downstream of the nozzle exit. The inner potential core ends around 8 diameters downstream of the nozzle exit and the mixing process then rapidly gains strength.

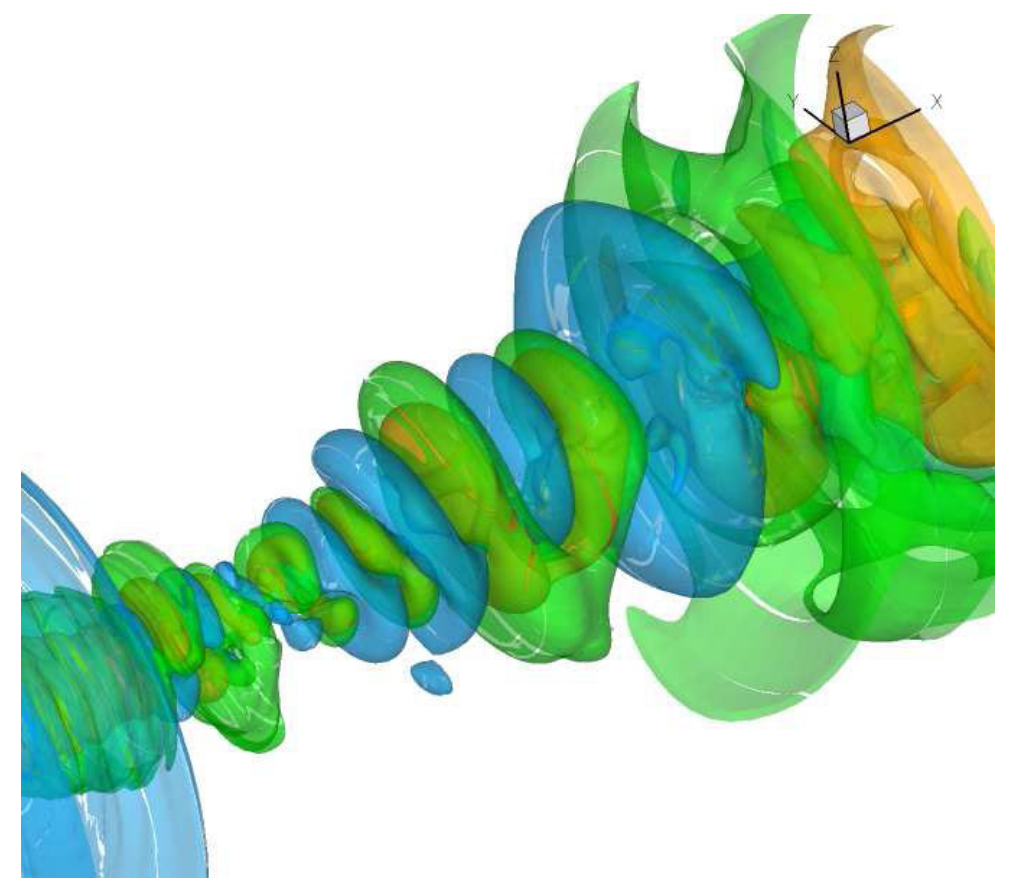

Figure 5. Instantaneous isobars at $t=440$, random forcing

Figure 5 shows the computed instantaneous three-dimensional pressure isosurfaces at $t=440$ for two levels, $p=0.71$ and $p=0.715$; the nondimensional ambient pressure is $1 / 1.4$. The isosurfaces show downstream radiating three-dimensional sound waves caused by the large-scale coherent structures in the jet flow, i.e., eddy-Mach wave radiation. Note that even though both the core and fan jets are subsonic, with theoretical Mach numbers of 0.90 and 0.97 , their theoretical acoustic Mach numbers are 1.4 and 0.95 . The computations show that the unsteady motion is a truly three-dimensional flow.

\section{B. Time-Averaged Data}

Figure 6 shows the radial variation of the time-averaged streamwise velocity for five streamwise stations, $x=1.11$, $5.12,8.42,11.73$, and 15.03. The solid lines and symbols represent the numerical results and the experimental data presented in Ref. 32, respectively. The computed result is in very good agreement with the experimental data at the first streamwise station indicating that the early jet shear layers are quite well resolved in the simulation. The agreement is also very good at the fourth station. At this station, $x=11.73$, the initial dual-core jet has evolved into a single-stream jet. Ref. 32 found experimentally that the jet flow is a self-similar single stream at locations greater than about six fan diameters downstream of the fan nozzle exit plane, which corresponds to about $x=11$ here. The numerical results are in general agreement with the experimental results for stations two, three, and five. The slight asymmetry clearly visible in the distribution for the last station indicates that a longer observation time is needed to fully capture the mean flow at this location. It may also indicate that not enough energy in the large-scale motions is being cascaded down to the small-scale motions and dissipated.

Figure 7 compares computed and experimental values for the radial distribution of $r m s$ streamwise velocity for three, $x=1.11,11.73$, and 15.03, of the streamwise stations above. The apparent discrepancy at the first station is because, at this location, the unsteady jet flow is still dominated by small scales, which of course can not be accounted for in the current LES simulation. The numerical values are representative of the applied forcing at the nozzle lip. However, the agreement between simulation and experimental results is good at the last two streamwise stations where the unsteady jet flow is dominated by large-scale structures. The asymmetry in the numerical result, that is also 

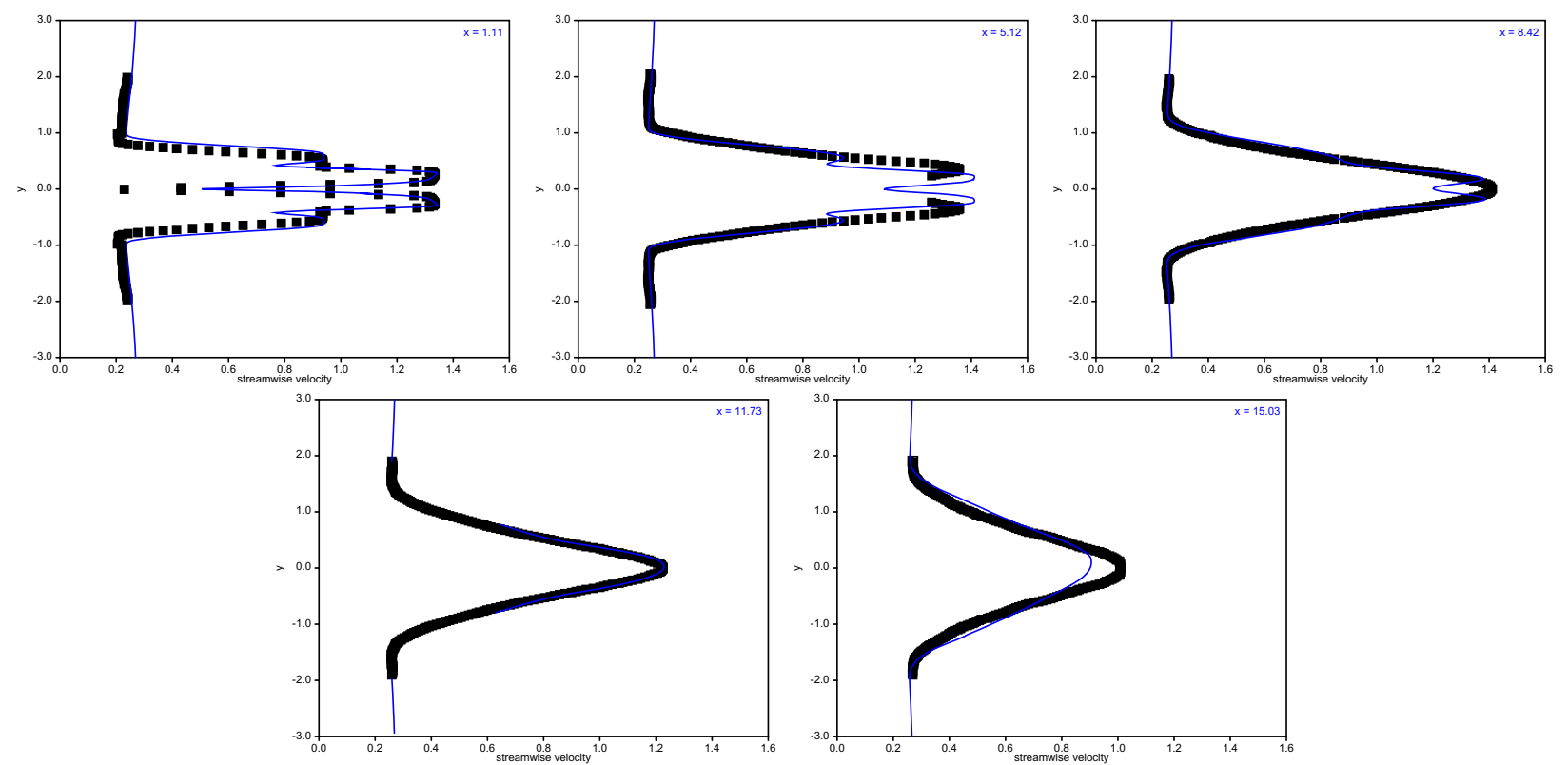

Figure 6. Radial variation of time-averaged streamwise velocity at five streamwise locations; symbols: experiment, ${ }^{32}$ solid lines: LES
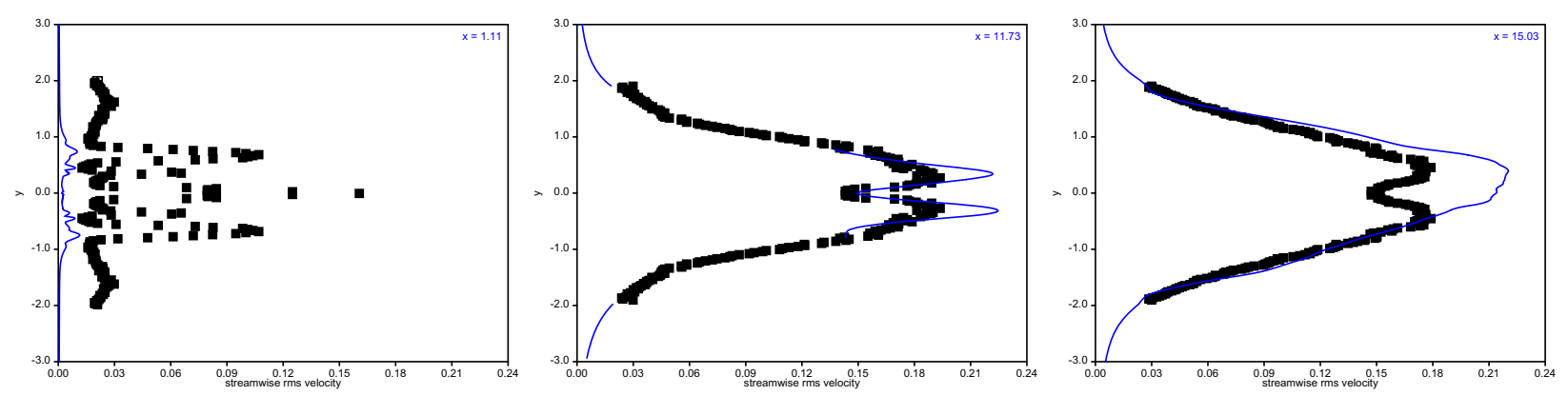

Figure 7. Radial variation of rms streamwise velocity at three streamwise locations; symbols: experiment, ${ }^{32}$ solid lines: LES

evident in the computed mean-flow profile above, is further evidence that the observation time at the last station is not long enough.

\section{Concluding Remarks}

The present mixing-noise computation for a subsonic coannular jet demonstrates that the near-field large-scale unsteady flow can be determined using a low-order (2nd order) finite-volume LES scheme, such as the current one. Instantaneous iso-surfaces of pressure show the radiating sound waves originating from the large-scale structures in the jet. These as well as instantaneous streamwise-velocity results demonstrate the highly unsteady and three-dimensional nature of the flow. Generally, the time-averaged results, such as for the streamwise velocity and rms streamwise velocity profiles agree well with existing experimental data. 


\section{References}

${ }^{1}$ Tam, C. K. W., “Jet Noise Generated by Large Scale Coherent Motion,” NASA RP-1258, pp. 311-390 (1991).

${ }^{2}$ Seiner, J. M., “Advances in High Speed Jet Aeroacoustics,” AIAA Paper 84-2275 (1984).

${ }^{3}$ Tam, C. K.W., "Supersonic Jet Noise,” Ann. Rev. Fluid Mech. vol. 27, pp. 17-43 (1995).

${ }^{4}$ Tam, C. K. W., “Computational Aeroacoustics: Issues and Methods," AIAA J. vol. 33, pp. 1788-1796 (1995).

${ }^{5}$ Tam, C. K. W., "Computational Aeroacoustics: An Overview of Computational Challenges and Applications," Inter. J. Comp. Fluid Dyn. vol. 18, pp. 547-567 (2004).

${ }^{6}$ Bailly, C. and Bogey, C., "Contributions of Computational Aeroacoustics to Jet Noise Research and Prediction," Inter. J. Comp. Fluid Dyn. vol. 18, pp. 481-491 (2004). (1998).

${ }^{7}$ Panda, J. and Seasholtz, R. G., "Density Measurement in Underexpanded Supersonic Jets Using Rayleigh Scattering," AIAA Paper 98-0281

${ }^{8}$ Panda, J. and Seasholtz, R. G., "Velocity and Temperature Measurement in Supersonic Free Jets Using Spectrally Resolved Rayleigh Scattering," AIAA Paper 99-0296 (1999).

${ }^{9}$ Panda, J. and Seasholtz, R. G., "Density Fluctuation Measurement in Supersonic Fully Expanded Jets Using Rayleigh Scattering," AIAA Paper 99-1870 (1999).

${ }^{10}$ Bridges, J. and Wernet, P. W., "Measurements of the Aeroacoustic Sound Source in Hot Jets," NASA/TM 2004-212508 (Also AIAA Paper 2003-3130) (2004).

${ }^{11}$ Bridges, J. and Wernet, P. W., "Cross-Stream PIV Measurements of Jets with Internal Lobed Mixers," AIAA Paper 2004-2896 (2004).

${ }^{12}$ Wernet, M. P., "Planar Particle Imaging Doppler Velocimetry: A Three-Component Velocity Measurement Technique," AIAA J. vol. 43, pp. 479-488 (2005).

${ }^{13}$ Tam, C. K. W. and Auriault, L., "Mean Flow Refraction Effects on Sound Radiated from Localized Sources in a Jet," J. Fluid Mech. vol. 370, pp. 149-174 (1998).

${ }^{14}$ Tam, C. K. W. and Auriault, L., "Jet Mixing Noise from Fine-Scale Turbulence," AIAA J. vol. 37, pp. 145-153 (1999).

${ }^{15}$ Tam, C. K. W. and Pastouchenko, N. N, "Noise from Fine-Scale Turbulence of Nonaxisymmetric Jets," AIAA J. vol. 40, pp. 456-464 (2003).

${ }^{16}$ Wundrow, D. W. and Khavaran, A., "On the Applicability of High-Frequency Approximations to Lilley's Equation," J. Sound Vibr. vol. 272, pp. 793-830 (2004).

${ }^{17}$ Mankbadi, R. R., Hayer, M. E. and Povinelli, L. A., “ Structure of Supersonic Jet Flow and Its Radiated Sound,” AIAA J. vol. 32, pp. 897-906 (1994).

${ }^{18}$ Zhao, W., Frankel, S. H. and Mongeau, L.,"Large Eddy Simulation of Sound Radiation from a Subsonic Turbulent Jet." AIAA Paper 2000-2078 (2000).

${ }^{19}$ Bogey, C., Bailly, C. and Juve, D. "Noise Investigation of a High Subsonic, Moderate Reynolds Number Jet Using a Compressible Large Eddy Simulation," Theor. Comp. Fluid Dyn. vol. 16, pp. 273-297 (2003).

${ }^{20}$ Uzun, A., Blaisdell, G. A. and Lyrintzis, A. S.,“3-D Large Eddy Simulation for Jet Aeroacoustics,” AIAA Paper 2003-3322 (2003).

${ }^{21}$ Debonis, J. and Scott, J., "A Large Eddy Simulation of a Turbulent Compressible Round Jet,” AIAA Paper 2001-2254 (2001).

${ }^{22}$ Loh, C.-Y. and Hultgren, L. S., "Near-Field Noise Computation for a Supersonic Circular Jet," AIAA Paper 2005-3042 (2005).

${ }^{23}$ Shur, M. L., Spalart, P. R., Strelets, M. Kh, and Garbaruk, A. V., "Further Steps in LES-Based Noise Prediction for Complex Jets," AIAA Paper 2006-485 (2006).

${ }^{24}$ Bodony, D. J. and Lele, S. K., "Review of the Current Status of Jet Noise Predictions Using Large-Eddy Simulation,” AIAA Paper $2006-486$ (2006)

${ }^{25}$ DeBonis, J. R,, "Progress Towards Large-Eddy Simulations for Predictions of Realistic Nozzle Systems," AIAA Paper $2006-487$ (2006).

${ }^{26}$ Mihăescu, M. and Gutmark, E. "Flow and Acoustics of a Coaxial Nozzle: a Sensitivity Study to the Inlet Boundary Conditions," AIAA Paper 2006-619 (2006).

${ }^{27}$ Tristanto, I. H., Page, G. J. and McGuirk, J. J., "Large Eddy Simulation of Hot Coaxial Jets,” AIAA Paper 2006-2497 (2006).

${ }^{28}$ Gröschel, E. R., Schröder, W. and Meinke, M., "Noise Generation Mechanisms in Single and Coaxial Jets," AIAA Paper $2006-2592$ (2006).

${ }^{29}$ Loh, C. Y. and Jorgenson, P. C. E., "A Time-Accurate Upwind Unstructured Finite-Volume Method for Compressible Flow with Cure of Pathological Behaviors," AIAA Paper 2007-4463 (2007).

${ }^{30}$ Quirk, J. J., “A Contribution to the Great Rieman Solver Debate," Int. J. Num. Meth. Fluids vol. 18, pp. 555-574 (1994).

${ }^{31}$ Gressier, J. and Mosshetta, J.-M., "On the Pathological Behavior of Upwind Schemes," AIAA Paper 98-0110 (1998).

${ }^{32}$ Koch, L. D., Bridges, J. and Kharavan, A, "Flowfield Comparisions From Three Navier-Stokes Solvers for an Axisymmetric Separate Flow Jet," AIAA Paper 2002-0672 (2002).

${ }^{33}$ Hirsch, C., Numerical Computation of Internal and External Flows, vol. 2, Wiley (1990).

${ }^{34}$ Steinbrenner, J. P. and Chawner, J. R., "Automatic Structured Grid Generation Using Gridgen (Some Restrictions Apply)," in Surface Modeling, Grid Generation, and Related Issues in CFD Solutions, NASA CP-3291 (1995),

${ }^{35}$ Karypis, G. and Kumar, V. "Multilevel k-way Partitioning Scheme for Irregular Graphs," Univ. of Minnesota Dept. of Comp. Sci./Army HPC Research Center Tech. Report 95-064 (1995).

${ }^{36}$ Anderson, D. A., Tannehill, J. C. and Pletcher, R. H., Computational Fluid Mechanics and Heat Transfer, MacGraw-Hill Book Company (1984)

${ }^{37}$ Loh, C. Y., Himansu, A. and Hultgren, L. S., "A 3-D Navier-Stokes Solver with Unstructured Hexahedral Grid for Computation of Nearfield Jet Screech Noise," AIAA Paper 2003-3207 (2003).

${ }^{38}$ Lesieur, M. and Métais, O., "New Trends in Large-Eddy Simulation of Turbulence," Ann. Rev. Fluid Mech. vol. 28, pp. 45-82 (1996).

${ }^{39}$ Fureby, C. and Grinstein, F. F., "Monotonically Integrated Large Eddy Simulation of Free Shear Flows," AIAA J., vol. 37, pp. 544-556 (1999).

${ }^{40}$ Loh, C. Y. and Hultgren, L. S., "Jet Screech Noise Computation," AIAA J. vol. 44, pp. $992-998$ (2006).

${ }^{41}$ van Albada, G. D., van Leer, B. and Roberts, Jr., W. W., "A Comparative Study of Computational Methods in Cosmic Gas Dynamics," Astronom. and Astrophys., vol. 108, pp. 76-84 (1982). 
${ }^{42}$ Loh, C. Y., "On a Non-Relecting Boundary Condition for Hyperbolic Conservation Laws,” AIAA Paper 2003-3975 (2003).

${ }^{43}$ Loh, C. Y. and Jorgenson, P. C. E., "A Robust Absorbing Boundary Condition for Compressible Flows," AIAA Paper 2005-4716 (2005).

${ }^{44}$ Loh, C. Y., Hultgren, L. S., and Jorgenson, P. C. E., "Near Field Screech Noise Computation for an Underexpanded jet by the CE/SE Method," AIAA Paper 2001-2252 (2001).

${ }^{45}$ Loh, C. Y. and Hultgren, L. S., "Jet Screech Noise Computation,” NASA/TM-2003-212626 (2003).

${ }^{46}$ Loh, C. Y. and Hultgren, L. S., "Computing Jet Screech - A Complex AeroacousticFeedback System”, presented at the 2nd Int'l Conference on CFD (ICCFD2), also NASA/TM-2002-211807 (2002).

${ }^{47}$ Jorgenson, P. C. E. and Loh, C. Y., “Computing Axisymmetric Jet Screech Tones Using Unstructured Grids”, AIAA Paper 2002-3889 (2002)

${ }^{48}$ Chang, S.-C., Wang, X.-Y. and Chow, C.-Y., "The Space-Time Conservation Element and Solution Element Method—A New High Resolution and Genuinely Multidimensional Paradigm for Solving Conservation Laws," J. Comp. Phys. vol. 159, pp. 89-136 (1999).

${ }^{49}$ Wang, X.-Y. and Chang S.-C., "A 2-D Non-splitting Unstructured Triangular Mesh Euler Solver Based on the Space-Time Conservation Element and Solution Element Method," C.F.D. J. vol. 8, pp. 309-325 (1999). 


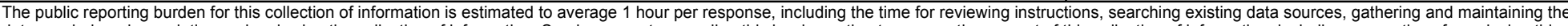

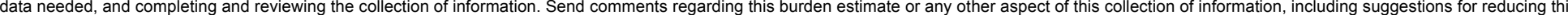

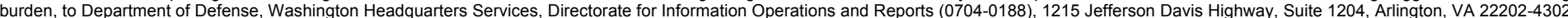

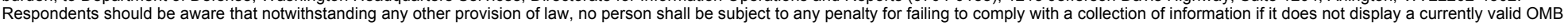
control number.

PLEASE DO NOT RETURN YOUR FORM TO THE ABOVE ADDRESS
1. REPORT DATE (DD-MM-YYYY)
2. REPORT TYPE

\section{DATES COVERED (From - To)}

01-02-2008

Technical Memorandum

\section{TITLE AND SUBTITLE}

Near-Field Noise Computation for a Subsonic Coannular Jet

5a. CONTRACT NUMBER

5b. GRANT NUMBER

5c. PROGRAM ELEMENT NUMBER

\section{5d. PROJECT NUMBER}

Loh, Ching, Y.; Hultgren, Lennart, S.; Jorgenson, Philip, C.E.

5e. TASK NUMBER

5f. WORK UNIT NUMBER

WBS 732759.03.01.02.02

\section{PERFORMING ORGANIZATION NAME(S) AND ADDRESS(ES)}

National Aeronautics and Space Administration

\section{PERFORMING ORGANIZATION} REPORT NUMBER

John H. Glenn Research Center at Lewis Field

E-16224

Cleveland, Ohio 44135-3191

\section{SPONSORING/MONITORING AGENCY NAME(S) AND ADDRESS(ES)}

National Aeronautics and Space Administration

Washington, DC 20546-0001

\section{TO. SPONSORING/MONITORS ACRONYM(S) \\ NASA}

11. SPONSORING/MONITORING REPORT NUMBER

NASA/TM-2008-215033

\section{DISTRIBUTION/AVAILABILITY STATEMENT}

Unclassified-Unlimited

Subject Categories: 01, 71, and 45

Available electronically at http://gltrs.grc.nasa.gov

This publication is available from the NASA Center for AeroSpace Information, 301-621-0390

\section{SUPPLEMENTARY NOTES}

\section{ABSTRACT}

A high-Reynolds-number, subsonic coannular jet is simulated, using a three-dimensional finite-volume LES method, with emphasis on the near field noise. The nozzle geometry used is the NASA Glenn 3BB baseline model. The numerical results are generally in good agreement with existing experimental findings.

\section{SUBJECT TERMS}

Computational aeronautics; Large-eddy simulation; Near-field jet noise; Co-axial jets

\begin{tabular}{|c|c|c|c|c|}
\hline \multicolumn{3}{|c|}{ 16. SECURITY CLASSIFICATION OF: } & \multirow{2}{*}{$\begin{array}{l}\text { 17. LIMITATION OF } \\
\text { ABSTRACT } \\
\text { UU }\end{array}$} & \multirow{2}{*}{$\begin{array}{l}\text { 18. NUMBER } \\
\text { OF } \\
\text { PAGES } \\
16\end{array}$} \\
\hline $\begin{array}{l}\text { a. REPORT } \\
U\end{array}$ & $\begin{array}{l}\text { b. ABSTRACT } \\
U\end{array}$ & $\begin{array}{l}\text { c. THIS } \\
\text { PAGE } \\
\text { U }\end{array}$ & & \\
\hline
\end{tabular}

19a. NAME OF RESPONSIBLE PERSON STI Help Desk (email:help@ sti.nasa.gov) 19b. TELEPHONE NUMBER (include area code) $301-621-0390$ 

